Moura, O., Simões, M. R., \& Pereira, M. (2015). Executive functioning in children with developmental dyslexia. The Clinical Neuropsychologist, 28(S1), 20-41. doi:10.1080/13854046.2014.964326

\title{
Executive Functioning in Children with Developmental Dyslexia
}

\section{Authors:}

Octávio Moura ${ }^{1}$

Mário R. Simões ${ }^{1}$

Marcelino Pereira ${ }^{1}$

${ }^{1}$ Faculty of Psychology and Education Sciences, University of Coimbra, Coimbra, Portugal.

\section{Correspondence concerning this article should be addressed to:}

Octávio Moura. Faculdade de Psicologia e de Ciências da Educação. Rua do Colégio Novo. Apartado 6153. 3001-802 Coimbra, Portugal. Phone: +351239851450.

Email: octaviomoura@gmail.com 


\title{
Executive Functioning in Children with Developmental Dyslexia
}

\author{
Abstract \\ The term executive function has been used to describe several higher-order cognitive \\ processes. This study examined the processing speed, shifting, planning, and verbal fluency of \\ a sample of 50 Portuguese children with developmental dyslexia (DD) and 50 typically \\ developing children (TDC; chronological-age-matched controls) between 8 and 12 years of \\ age to evaluate the children's executive functioning. Compared to TDC, children with DD \\ revealed significant processing speed, shifting, and verbal fluency deficits. After controlling \\ for differences in the general intellectual ability, significant group differences remained for \\ shifting, verbal fluency and marginally for processing speed. No significant differences in \\ planning ability were observed between the groups. No significant interaction of group, \\ gender, and age was found for any of the executive functions measures studied. Word \\ productivity in both semantic and phonemic verbal fluency tasks decreased significantly over \\ the 60 seconds for both groups. Shifting was the only significant predictor of DD in the binary \\ logistic regression analysis and yielded the highest area under the curve value (receiver \\ operating characteristics curve analysis). Therefore, although these findings highlight the \\ presence of specific executive functions deficits in children with DD, they should not be \\ interpreted as indicative of the presence or absence of this learning disorder.
}

Keywords: processing speed, planning, shifting, verbal fluency, developmental dyslexia

\section{Introduction}

Developmental dyslexia (DD) is a specific learning disability that is neurobiological in origin and characterized by difficulty with accurate and/or fluent word recognition and by poor spelling and decoding abilities. These traits typically result from a phonological deficit (Lyon, 
Shaywitz, \& Shaywitz, 2003) and are not a consequence of sensory impairments, low intelligence or a lack of educational opportunities (American Psychiatric Association, 2013).

A large number of studies have supported the hypothesis that phonological processing is the most relevant neurocognitive phenotype of DD in opaque and transparent orthographies (Landerl et al., 2013; Ramus, Marshall, Rosen, \& van der Lely, 2013). Although deficits are most pronounced in measures of phonological processing, other studies suggest that individuals with DD also have weaknesses in other neurocognitive domains. Traditionally, neuropsychological models of neurodevelopmental disorders have typically proposed that a single primary neurocognitive deficit was sufficient to explain all of the symptoms observed for a disorder. Recently, some researchers have challenged the validity of single-deficit models and suggested the presence of a multiple cognitive deficit model for understanding “complex" neurodevelopmental disorders, such as DD, attention-deficit hyperactivity disorder (ADHD), dyscalculia, and other disorders (Pennington, 2006; Willcutt et al., 2013; Willcutt, Sonuga-Barke, Nigg, \& Sergeant, 2008). For instance, Willcutt, Pennington, Olson, Chhabildas, and Hulslander (2005) found evidence of a cognitive overlap between DD and ADHD, in which both neurodevelopmental disorders were associated with weaknesses on most cognitive measures [more pronounced in measures of processing speed (PS)]. Similarly, shared neuropsychological weaknesses were observed between children with DD and dyscalculia (Willcutt et al., 2013).

Therefore, impairment in executive functions $(\mathrm{EF})$ is ubiquitous across neurodevelopmental disorders, although distinct profiles emerge from various aspects of EF (Willcutt et al., 2008). Many studies have consistently found that children with DD exhibit weaknesses on a range of EF measures (Altemeier, Abbott, \& Berninger, 2008; Brosnan et al., 2002; Helland \& Asbjørnsen, 2000; Moura, Simões, \& Pereira, 2014b; Reiter, Tucha, \& Lange, 2005; Varvara, Varuzza, Sorrentino, Vicari, \& Menghini, 2014), which are not simply 
secondary consequence of a deficit in another domain (Willcutt et al., 2008). Nonetheless, the literature has been discordant concerning which executive processes are compromised in DD. Therefore, the present study examined the presence of specific deficits in the executive functioning of children with DD who were native speakers of an orthography of intermediate depth (European Portuguese orthography). We also investigated the diagnostic accuracy of EF measures to correctly discriminate between typically developing children (TDC) and children with DD.

EF is a shorthand description of a complex set of processes associated with the metacognitive capacities that allow an individual to perceive stimuli in his or her environment, respond adaptively, flexibly change direction, anticipate future goals, consider consequences, and respond in an integrated way (Baron, 2004). Studies of brain-damaged patients and neuroimaging studies have located EF in the frontal (particularly the prefrontal cortex) and parietal lobes (Collette, Hogge, Salmon, \& Van der Linden, 2006; Demakis, 2004; Wager \& Smith, 2003). For example, the ability to maintain verbal information in working memory has been found to rely primarily on the lateral prefrontal cortex (Narayanan et al., 2005), switching ability has been associated with the medial prefrontal cortex and posterior parietal cortex (Collette et al., 2006; Crone, Wendelken, Donohue, \& Bunge, 2006), the ability to inhibit responses was found to rely on the right inferior frontal cortex (Aron, Robbins, \& Poldrack, 2004), and updating was associated with cerebral activity in the prefrontal (dorsolateral, inferior and cingulate) and parietal (posterior and superior) areas (Collette et al., 2006). Although the frontal and parietal lobes play an important role in the mediation of EF, researchers also agree that the integrity of the entire brain is necessary for efficient executive functioning (Stuss \& Alexander, 2000; Tamnes et al., 2010).

So, the current conceptualizations support the idea of a fronto-parietal network supporting executive processes, which is relevant in light of the recent findings about the 
involvement of frontal and parietal areas in DD (Bloom, Garcia-Barrera, Miller, Miller, \& Hynd, 2013; Boets et al., 2013). Reading development requires the coordination of many aspects of cognition; therefore, it is not surprising that early reading skills (Foy \& Mann, 2013), reading comprehension (Borella \& de Ribaupierre, 2014; Sesma, Mahone, Levine, Eason, \& Cutting, 2009) and reading decoding (Altemeier et al., 2008; Bental \& Tirosh, 2007) have been associated with specific executive processes, particularly working memory, inhibition and shifting. For example, working memory plays an important role in reading comprehension because it enables readers to process and access text information to build a coherent representation of the text's meaning. Cognitive inhibition has also frequently been considered in reading comprehension to contribute to selecting of relevant items, to enable individuals to form a coherent representation of the text (Borella \& de Ribaupierre, 2014).

Neurodevelopmental studies have shown that executive functioning emerges in early childhood, develops significantly throughout childhood and adolescence, and that adult-level performance on the most complex EF tasks does not occur until adolescence or even early adulthood (V. Anderson, Anderson, Northam, Jacobs, \& Catroppa, 2001; Best \& Miller, 2010; Davidson, Amso, Anderson, \& Diamond, 2006). Indeed, executive processes are subject to distinct developmental trajectories. Anderson (2002) found that attentional control appears to emerge in infancy and develops rapidly in early childhood, whereas cognitive flexibility, goal setting, and information processing experience a critical period of development between 7 and 9 years of age, and are relatively mature by 12 years of age. Additionally, working memory capacity has been found to gradually develop throughout childhood and into young-adulthood, shifting attained mature levels during adolescence (Huizinga, Dolan, \& van der Molen, 2006), whereas inhibition was found to reach adult-level performance in late childhood or adolescence (Bedard et al., 2002; van den Wildenberg \& van der Molen, 2004). These findings about the influence of age on EF task performance have 
also been supported by neuroimaging studies examining the maturation of frontal lobe (Blakemore \& Choudhury, 2006; Tamnes et al., 2010). Studies about the influence of gender differences on EF task performance have reported inconsistent findings. Though some studies have indicated that boys and girls develop executive functioning in similar ways during childhood (Davidson et al., 2006; Marzocchi et al., 2008), others have observed gender differences on specific tasks (V. Anderson et al., 2001; Rosselli, Ardila, Bateman, \& Guzman, 2001). These differences may be related to gender-specific differences in brain development (De Bellis et al., 2001; Giedd et al., 1996).

Despite its wide acceptance, conceptually defining EF has been difficult. There is no consensus among researchers about the executive components involved (for a review, see Chan, Shum, Toulopoulou, \& Chen, 2008; Jurado \& Rosselli, 2007; Wasserman \& Wasserman, 2013). Some researchers have conceptualized EF as a single construct (Sala, Gray, Spinnler, \& Trivelli, 1998), but others view it as comprising multiple process-related systems (Alexander \& Stuss, 2000). As Anderson (2002, p. 73) stated, "this latter framework is probably more accurate given that global executive impairment is rare, specific executive processes are thought to be associated with distinct frontal systems, and executive processes demonstrate variable developmental profiles". Factor analytic-studies have identified multiple EF components. For instance, Welsh, et al. (1991) identified three factors reflecting speeded responding, set maintenance, and planning. Miyake et al. (2000) examined three oftenpostulated aspects of EF (shifting, inhibition, and updating ) through a confirmatory factor analysis and found that, although they are distinguishable, they share some underlying commonality. Anderson (2002) proposed four distinct domains: attentional control, information processing, cognitive flexibility, and goal setting.

Another problem affecting the measurement of executive functioning is the "task impurity problem" (Miyake et al., 2000; van der Sluis, de Jong, \& van der Leij, 2007). EF 
regulates other cognitive processes, and assessing them requires other non-executive cognitive abilities to be considered (e.g., verbal and visual-spatial abilities, motor speed, or attention). Furthermore, executive tasks often require more than one executive function and the intercorrelations among EF tasks are low to moderate (Lehto, Juujärvi, Kooistra, \& Pulkkinen, 2003; Miyake et al., 2000).

Despite these methodological issues, there exists a relative agreement in terms of the complexity and importance of executive functioning to human adaptive behavior. EF measures are widely used in clinical neuropsychological assessment and typically include (but are not limited to) PS, planning, shifting, verbal fluency (VF), inhibition, updating, divided attention, and working memory tasks. PS, shifting, planning, and VF tasks are the measures most often used in studies of children with DD (Brosnan et al., 2002; Reiter et al., 2005; Shanahan et al., 2006) and in clinical evaluations. Therefore, these four tasks were used to explore EF deficits in Portuguese-speaking children with DD in the present study.

\section{Processing Speed}

PS is the ability to automatically and fluently perform relatively easy or over-learned elementary cognitive tasks, especially when high mental efficiency is required (McGrew, 2009). The Coding and Symbol Search subtests from the Processing Speed Index of the Wechsler Intelligence Scale for Children (WISC) are two of the most common tasks used to measure PS performance among children and adolescents. These subtests also measure visualmotor coordination, scanning ability and visual perception (Kaufman \& Lichtenberger, 2000; Martins, Maruta, Freitas, \& Mares, 2013).

Several studies have found that children with DD showed deficits on both WISC-III Processing Speed Index subtests (Moura, Simões, \& Pereira, 2014a; Thomson, 2003). Shanahan et al. (2006) performed a detailed study that examined the presence of PS deficits in 
children and adolescents with DD and ADHD using a wide range of PS tasks. The results suggested that, compared to TDC, a general PS deficit exists in both clinical groups but that children with DD showed greater PS deficits than children with ADHD. Likewise, Willcutt et al. (2005) also found that children with DD or ADHD performed worse than TDC on five PS tasks. More recently, Peng, Sha, and Li (2013) also observed that TDC outperformed children with DD on all PS tasks in a sample of Chinese children.

Catts, Gillispie, Leonard, Kail, and Miller (2002) found that PS explained unique variance in reading comprehension and word recognition even when Full Scale IQ (FSIQ) and rapid naming were introduced into the regression model first. Rapid naming, however, did not predict the additional variance in these two reading measures after FSIQ and PS were taken into account. The authors hypothesized that PS deficit may be an extra-phonological factor in some reading disabilities.

\section{Shifting}

Shifting has been conceptualized as the ability to flexibly switch between multiple tasks, strategies, or mental sets (Miyake et al., 2000; van der Sluis, de Jong, \& van der Leij, 2004; van der Sluis et al., 2007). Miyake et al. (2000) suggested that shifting is a basic underlying component of executive functioning, which is implicated in the performance of more complex executive tasks. A recent meta-analytic study found that shifting was significantly associated with children's performance in both reading and math (Yeniad, Malda, Mesman, van Ijzendoorn, \& Pieper, 2013). While some studies have observed that children with DD have difficulty performing tasks that rely on shifting (Helland \& Asbjørnsen, 2000; HorowitzKraus, 2012; Menghini et al., 2010), others did not find significant differences between children with DD and TDC (Bental \& Tirosh, 2007; Reiter et al., 2005). 
The Wisconsin Card Sorting Test (WCST) and the Trail Making Test (TMT) - Part B are often used to measure shifting ability. Willcutt and colleagues (2005) found that children with DD scored significantly lower than controls on TMT-B and WCST perseverative errors scores. These main effects did not remain significant after controlling for FSIQ, suggesting that shifting difficulties associated with DD may be explained by group differences in general intelligence. Other studies that used the WCST revealed that individuals with DD committed more perseverative errors (Marzocchi et al., 2008) and more non-perseverative errors (Helland \& Asbjørnsen, 2000) and completed fewer categories (Helland \& Asbjørnsen, 2000; Menghini et al., 2010) than typically developing individuals. Narhi and colleagues (1997) found that children with DD performed worse on the TMT-B but not on the TMT-A than TDC. They hypothesized that the poorer performance of children with DD on the TMT-B might reflect the difficulty those with DD have in following the alphabetical series. In the studies of both Reiter et al. (2005) and van der Sluis et al. (2004), the results of TMT-B showed non-significant differences between children with DD and chronological-age controls.

\section{Planning}

Planning ability is one of the major aspects of executive functioning and has been described as the ability to identify and organize the steps and elements that are required to achieve a goal (Lezak, Howieson, \& Loring, 2004). In clinical neuropsychology, planning ability is assessed most often using the Tower of London (ToL) and the Tower of Hanoi (ToH) tests or one of their variants.

Studies testing the planning ability of children with DD have yielded inconsistent findings. Condor, Anderson, and Saling (1995) found that young TDC require significantly fewer trials to reach a successful solution to five-problem variations of the ToH than children with DD, but no significant differences were observed among older children. DD and typical 
readers did not obtain significantly different scores for number of errors, initial thinking time, or subsequent thinking time in Brosnan et al.'s (2002) study. Reiter et al. (2005) used the ToL to measure differences in planning abilities between children with DD and TDC. They found that the groups did not differ in the number of problems solved but that the planning time was significantly longer in the DD group. Marzocchi et al. (2008), who also used the ToL, did not find significant group differences in total score, planning time, or execution time.

\section{Verbal Fluency}

VF tests require participants to retrieve words based on semantic (subjects should produce as many different words as possible within a particular semantic category, e.g., animals, food, names) and phonemic (subjects should produce as many different words as possible that begin with a particular letter, e.g., the letters F, A, or S) criteria within a time constraint (Lezak et al., 2004). VF tests have been used to measure specific aspects of EF, memory, and language. Several neuroimaging studies have suggested that although both semantic and phonemic fluency tasks are associated with frontal and temporal lobe processes, phonemic tasks are more dependent on the frontal lobe and semantic tasks on the temporal lobe (Baldo, Schwartz, Wilkins, \& Dronkers, 2006; Birn et al., 2010).

Empirical research has shown that children with DD generate significantly fewer words than TDC in phonemic VF tasks; for semantic VF tasks, however, inconsistent findings have been reported (Landerl, Fussenegger, Moll, \& Willburger, 2009; Marzocchi et al., 2008; Reiter et al., 2005). Cohen and colleagues (1999) found that phonemic VF tasks were clinically useful in differentiating two subgroups of children with DD (dysphonetic and dyseidetic) and that the performance of dysphonetic children was significantly lower than that of children with ADHD. Furthermore, semantic VF tasks have been shown to be easier than phonemic VF tasks for TDC (Filippetti \& Allegri, 2011; Martins, Vieira, Loureiro, \& Santos, 
2007; Moura, Simões, \& Pereira, 2013; Riva, Nichelli, \& Devoti, 2000) and for children with DD (Reiter et al., 2005; Varvara et al., 2014). Researchers have hypothesized that semantic tasks are easier because phonemic tasks depend more on the maturation of the frontal lobe; to retrieve words beginning with a letter, an individual must explore more category subsets than is required to retrieve words within a semantic category (Riva et al., 2000).

Troyer (2000) and Hurks et al. $(2004 ; 2006)$ argued that the total number of words an individual can generate in 60 seconds does not provide sufficient information about the specific cognitive mechanisms that underlie poor performance on VF tasks. They suggested other scoring methods that measured (i) word productivity as a function of time and/or (ii) systematic organization of information, such as clustering (i.e., the production of two or more words within the same semantic or phonemic subcategory) and switching (i.e., the ability to shift between subcategories). The few studies that have analyzed word productivity as a function of time in children found that word production decreased significantly over time (Filippetti \& Allegri, 2011; Hurks, 2012; Hurks et al., 2006; Moura et al., 2013; Takács, Kóbor, Tárnok, \& Csépe, 2014). No studies have analyzed children with DD. Using the second alternative scoring method, Troyer et al. (2000; Troyer, Moskovitch, \& Winocur, 1997) and other authors (Hurks, 2012; Unsworth, Spillers, \& Brewer, 2010) demonstrated that clustering and switching are dissociable components of VF performance. Both skills were equally important in semantic VF tasks, but switching made a greater contribution to phonemic VF than did clustering, possibly because switching is more related to frontal lobe functioning.

Although an increasing number of studies about EF in DD have been published recently, inconsistent findings have been obtained. Therefore, the present study has two main objectives: (i) to examine the presence of specific deficits in the executive functioning of Portuguese-speaking children with DD and (ii) to analyze the ability of four different EF 
measures (PS, shifting, planning, and VF) to accurately discriminate between children with DD and TDC. Based on the existing literature from different languages spanning a large range of orthographic complexities (e.g., Norwegian: Helland \& Asbjørnsen, 2000; Italian: Marzocchi et al., 2008; German: Reiter et al., 2005; English: Willcutt et al., 2005), we expected that Portuguese-speaking children with DD would show significant impairment in the EF measures. We also expected that EF tasks would be accurate measures for distinguished children with DD from TDC. Currently, no studies have analyzed the diagnostic accuracy of EF measures for discriminating between subjects (DD vs. TDC) or have analyzed the executive functioning in Portuguese-speaking children with DD (the European Portuguese orthography is considered to be an intermediate depth). The large body of research about EF deficits in DD has been conducted in English-speaking samples (opaque orthography).

\section{Method}

\section{Participants}

The participants included 100 Portuguese children between the ages of 8 and $12(M=9.81$; $S D=1.34)$ in grades 3 through 6. In the DD group $(N=50), 74 \%$ were male and $26 \%$ were female, with a mean age of 9.80 years $(S D=1.38)$. Among the children with DD, $26 \%$ had undergone school retention, $36 \%$ were included in special education system, and $30 \%$ had relatives with reading difficulties. In the TDC group $(N=50), 64 \%$ were male and $36 \%$ were female, with a mean age of 9.82 years $(S D=1.32)$. Only $2 \%$ had experienced school retention, and $4 \%$ had relatives with reading difficulties. The children in the DD and TDC groups were matched for age $\chi^{2}(4)=0.487, p=.975$, yielding non-significant differences in gender $\chi^{2}(1)=1.169, p=.387$ and grade $\chi^{2}(3)=1.776, p=.620$. 
Criteria for inclusion. For both groups, only children who met the following criteria were included in the study: (i) WISC-III FSIQ $\geq 90$; (ii) native speakers of European Portuguese; (iii) at least two years of school attendance; (iv) absence of a visual, hearing, or motor handicap; (v) never diagnosed with a language impairment, emotional disturbance, dyscalculia, disruptive behavior disorder (ADHD, oppositional defiant disorder, and conduct disorder), neurological impairment, or other psychiatric disorder. Children with special educational needs were excluded from the TDC group.

All subjects attended regular classes in public and private Portuguese schools. Children with DD were recruited for participation through contact with school psychologists and special education teachers, and referrals from the medical, psychological and other educational/clinical professions (e.g., teachers and speech therapists). The TDC group was recruited through contact with teachers, parents and other participants using a snowball sampling strategy. In the DD group, only children who had previously been diagnosed with DD by a psychologist, child psychiatrist, developmental pediatrician, or child neurologist and had received a score lower than or equal to the $15^{\text {th }}$ percentile on a reading fluency and accuracy measure ("O Rei"; Carvalho \& Pereira, 2009) administered during the testing session were included. These cut-off criteria (WISC-III FSIQ $\geq 90$ and reading fluency and accuracy measures $\leq 15^{\text {th }}$ percentile) are similar (and in some cases stricter than) the inclusion criteria used by other studies (e.g., Bental \& Tirosh, 2007; Frijters et al., 2011; Gooch, Snowling, \& Hulme, 2011; Reiter et al., 2005; Swanson, 2011). For the TDC group, only children with a score greater than the 40th percentile on both reading measures were included.

\section{Measures and Procedures}

Intellectual ability. The Portuguese version of the WISC-III (Wechsler, 2003) was administered to measure general intellectual ability. The General Ability Index (GAI) scores 
were analyzed and used as a covariate in the inferential analysis. The WISC-III GAI is a composite score, which is derived from the four Verbal Comprehension Index subtests and the four Perceptual Organization Index subtests (Prifitera, Weiss, \& Saklofske, 1998). We used GAI (rather than FSIQ) because it excludes subtests that are related to EF (i.e., PS and working memory). As suggested by Saklofske, Prifitera, Weiss, Rolfhus, and Zhu (2005), in some special educational cases (e.g., children with learning disability and ADHD), the GAI may be a slightly higher estimate of overall intellectual ability than the FSIQ.

Processing Speed. The Coding and Symbol Search subtests from the WISC-III and the TrailA test from the Coimbra Neuropsychological Assessment Battery (BANC; Simões et al., in press) were used to measure PS. The Coding (Form B) subtest requires that the child rapidly copy (in two minutes) nine types of symbols, each paired with a number, using a key provided at the top of the page. The Symbol Search (Form B) subtest requires that the child match a specific symbol to an identical target that is displayed among several distracter stimuli. This test also lasts for two minutes. Age-scaled scores $(M=10, S D=3)$ from the Portuguese version of the WISC-III (Wechsler, 2003) were used for both tasks. The Trail-A test requires the child to draw a line sequentially connecting 25 encircled numbers ( 1 through 25$)$ randomly distributed on a sheet of paper (similar to the TMT-A). The raw score of the Trail-A test represents the amount of time (in seconds) taken to complete the task.

Shifting. The Trail-B test from the BANC (Simões et al., in press) was administered to examine participants' shifting ability (similar to the TMT-B). This test requires the child to draw a line connecting 25 circles containing numbers or letters randomly distributed on a sheet of paper, alternating between numbers and letters (1, A, 2, B, etc.). The Trail-B is more complex than the Trail-A because it makes greater demands on an individual's rapid visual 
scanning and visuospatial sequencing capacities and involves cognitive shifting, flexibility, and divided attention. The raw score of the Trail-B represents the amount of time (in seconds) taken to complete the task.

Planning. The Tower test from the BANC (Simões et al., in press) was used to assess planning and problem solving abilities (similar to the ToL). The test comprises 14 models that the child is asked to reproduce by creating a tower using three balls of different colors (red, blue, and green) and three pegs (large, medium, and small). The child must move the three colored balls to specific positions on the three pegs in a specific number of moves (starting with one move and gradually increasing to five moves). The child has four trials in which to correctly solve each of the 14 models. Three raw scores were analyzed: Correct First Trials (i.e., the total number of models correctly solved on the first trial; range $=0-14$ ), Correct Models (i.e., the total number of models correctly solved; range $=0-14$ ), and Total Trials (i.e., the total number of trials taken to solve the 14 models; range $=14-56$ ).

Verbal Fluency. The Semantic and Phonemic Verbal Fluency test from the BANC (Simões et al., in press) comprises three semantic (Animals, Names, and Food) and three phonemic (letters P, M, and R) tasks. VF tests have been used extensively in neuropsychological assessments to measure executive functioning, executive aspects of language processing, and semantic memory. For each of the semantic and phonemic tasks, the child was asked to generate as many words as possible within a time constraint of 60 seconds. The raw score was the total number of correct words (different forms of the same word were excluded) generated within the time limit for the three semantic or phonemic tasks. Additionally, to analyze word productivity as a function of time, the number of words generated by the child were recorded 
over four time intervals ( $0-15$ seconds, $16-30$ seconds, $31-45$ seconds, and 46-60 seconds), as recommended by Hurks et al. (2004; 2006).

The administration of these tasks was part of a broad neuropsychological protocol that also included measures of intelligence, memory, attention, language, reading, and spelling. The children were tested in two sessions separated by a 10- to 15-day interval. The sessions were approximately 90-minutes long and took place in a clinic or school setting during a regular day.

\section{Statistical Analyses}

The statistical analyses were performed using IBM SPSS Statistics 19. Group differences were analyzed using a multi-factorial multivariate analysis of variance (MANOVA) and covariance (MANCOVA). Group, gender, and age were included as fixed factors, and the executive functions measures were used as dependent variables. If the multivariate analysis (Pillai's trace) indicated a significant overall difference $(p<.05)$, then a univariate test was applied to determine which dependent variables were responsible for the multivariate difference. In specific cases, univariate analysis of covariance (ANCOVA), repeated measures ANOVAs and independent- and paired-samples t-tests were also used. Cohen's $d$ or partial eta-squared $\left(\eta_{p}^{2}\right)$ was also calculated to determine the effect size of the differences between groups.

A receiver operating characteristics (ROC) curve and binary logistic regression analysis were also performed to examine the accuracy with which EF tasks were able to discriminate between children in the DD and TDC groups. A ROC curve analysis systematically sweeps across all possible true positive (sensitivity) and false positive (1specificity) values of a diagnostic test and calculates the area under the curve (AUC), which provides an accuracy index of the test (Fawcett, 2006). An AUC of .5 to .7 indicates low test 
accuracy, .7 to .9 moderate accuracy, and .9 to 1.0 high accuracy (Swets, 1988). For the binary logistic regression analysis, the fit of the model (Hosmer-Lemeshow test, Cox and Snell $R^{2}$, and Nagelkerke $R^{2}$ ) and the statistical tests of individual predictors were analyzed (regression coefficient, Wald's $\chi^{2}$, and odds ratio).

\section{Results}

\section{Processing Speed}

A 2 X 2 X 5 (group X gender X age) MANOVA was performed and a significant main effect was observed for group, $F(3,78)=4.073, p=.010, \eta_{\mathrm{p}}^{2}=.135$. The univariate analysis revealed significant effects in Coding, $\left.F(1,80)=4.823, p=.031, \eta_{\mathrm{p}}^{2}=.057\right)$, Symbol Search, $\left.F(1,80)=7.269, p=.009, \eta_{\mathrm{p}}^{2}=.083\right)$, and Trail-A, $\left.F(1,80)=6.274, p=.014 ; \eta_{\mathrm{p}}^{2}=.073\right)$ Children with DD scored significantly lower than TDC (see Table 1).

No significant group $\mathrm{X}$ gender, $F(3,78)=0.330, p=.804, \eta^{2} \mathrm{p}=.013$, group $\mathrm{X}$ age, $F(12,240)=0.824, p=.625, \eta^{2} \mathrm{p}=.040$, or group $\mathrm{X}$ gender $\mathrm{X}$ age interactions, $F(9,240)=$ $0.604, p=.793, \eta_{\mathrm{p}}^{2}=.022$, were found.

(Table 1 about here)

\section{Shifting}

A 2 X 2 X 5 (group X gender X age) ANCOVA was performed with Trail-B as a dependent variable and Trail-A as a covariate in order to "isolate" the shifting effect on the Trail-B. A significant main effect for group was observed, $F(1,80)=10.371, p=.002, \eta^{2}{ }_{p}=.115$. Children with DD took more time than TDC to complete the Trail-B (see Table 1). No significant interactions were observed for group $\mathrm{X}$ gender, $F(1,80)=0.004, p=.953, \eta_{\mathrm{p}}^{2}<$ .001 , group $\mathrm{X}$ age, $F(4,80)=0.559, p=.693, \eta_{\mathrm{p}}^{2}=.027$, or group $\mathrm{X}$ gender $\mathrm{X}$ age, $F(3,80)=$ $0.149, p=.930, \eta^{2}{ }_{p}=.006$. 
As previously noted, Trail-B is a more complex task than Trail-A because it makes greater cognitive demands. To examine this hypothesis, two paired-samples t-tests were performed for each group. The results indicated that TDC, $t(49)=13.773, p<.001, d=2.27$, and children with DD, $t(49)=15.191, p<.001, d=2.54$, take more time to complete the Trail-B than the Trail-A.

\section{Planning}

A multi-factorial MANOVA performed on the three Tower scores yielded a non-significant main effect for group, $F(3,79)=0.915, p=.438, \eta^{2}{ }_{p}=.034$, and for the group X gender, $F(3$, $79)=2.034, p=.116, \eta_{\mathrm{p}}^{2}=.072$, group $\mathrm{X}$ age, $F(12,243)=1.297, p=.221, \eta_{\mathrm{p}}^{2}=.060$, and group $\mathrm{X}$ gender $\mathrm{X}$ age interactions, $F(9,243)=0.825, p=.593, \eta_{\mathrm{p}}^{2}=.030$ (see Table 1$)$.

\section{Verbal Fluency}

The performance scores of TDC and children with DD on Semantic and Phonemic VF tests are shown in Table 1. The scores on the two tasks tapping VF were entered into a MANOVA as dependent variables and group, gender and age as fixed factor. The multivariate main effect of group proved to be significant, $F(2,80)=7.975, p=.001, \eta^{2}{ }_{p}=.166$. At the univariate level, significant group differences were observed for Semantic VF, $F(1,81)=10.479, p=$ $.002, \eta_{\mathrm{p}}^{2}=.115$, and Phonemic VF, $F(1,81)=12.579, p=.001, \eta_{\mathrm{p}}^{2}=.134$. Children with DD produced significantly fewer words within the 60 -second time limit than TDC on both VF tests. No significant interactions were observed for group $\mathrm{X}$ gender, $F(2,80)=0.516, p=$ $.599, \eta^{2} \mathrm{p}=.013$, group $\mathrm{X}$ age, $F(8,162)=1.525, p=.152, \eta^{2} \mathrm{p}=.070$, and group $\mathrm{x}$ gender $\mathrm{x}$ age, $F(6,162)=1.372, p=.229, \eta_{\mathrm{p}}^{2}=.048$. For the TDC and DD groups [TDC: $t(49)=$ 21.033, $p<.001, d=3.02$; DD: $t(49)=25.170, p<.001, d=3.22]$, the higher number of words produced within the time limit were observed on the Semantic VF (see Table 1). 
To analyze the performance of both groups over four time intervals ( $0-15$ seconds; $16-$ 30 seconds; $31-45$ seconds; and 46-60 seconds) on the Semantic VF and Phonemic VF tests, we performed four repeated measures ANOVAs. As shown in Table 2, the number of words produced in each of the four time intervals differed significantly, with word production decreasing over time in both VF measures. The Bonferroni adjustment for multiple comparisons revealed the presence of significant differences among all the time intervals in the Semantic VF task and almost all the time intervals in the Phonemic VF task for both groups. As expected, children tended to produce more words in the first 15 seconds than in the remaining three time intervals. Additional independent-samples t-tests revealed statistically significant differences between the TDC and DD groups in the first two time intervals of both VF tasks, $0-15$ seconds: $t_{\mathrm{SVF}}(98)=3.986, p<.001, d=0.79 ; t_{\mathrm{PVF}}(98)=$ $2.582, p=.011, d=0.51 ; 16-30$ seconds: $t_{\mathrm{SVF}}(98)=2.576, p=.011, d=0.51 ; t_{\mathrm{PVF}}(98)=$ 2.824, $p=.006, d=0.56$.

(Table 2 about here)

\section{Group Differences on Executive Functions after controlling for WISC-III GAI}

The WISC-III GAI scores differed significantly, $t(98)=3.569, p<.001, d=0.71$, between the TDC and the children with DD (sum of the eight age-scaled scores that enter the Verbal Comprehension Index and the Perceptual Organization Index; TDC group: $M=88.76 \pm$ 13.02, and DD group: $M=80.31 \pm 10.36$ ). Therefore, we additionally examined whether GAI scores could explain the group differences on EF tasks. A series of 2 X 2 X 5 (group X gender $\mathrm{X}$ age) MANCOVAs and ANCOVAs, covarying WISC-III GAI, were conducted on all EF tasks. After controlling for differences in general intellectual ability, the main effect of group remained significant for shifting, $F(1,79)=7.616, p=.007, \eta^{2} \mathrm{p}=.089$, for $\mathrm{VF}, F(2,78)=$ 3.901, $p=.024, \eta^{2}{ }_{\mathrm{p}}=.091$ (univariate analysis: Semantic VF, $p=.022$; Phonemic VF, $p=$ 
.022 ), and marginally significant for PS, $F(3,77)=2.727, p=.050, \eta^{2}{ }_{p}=.096$ (univariate analysis: Coding, $p=.113$; Symbol Search, $p=.020$; Trail-A, $p=.063)$. In contrast, none of the interactions or the main effect of group for planning were significant.

\section{ROC Curve and Binary Logistic Regression Analysis}

Although the findings presented above report the presence of significant differences in EF between TDC and children with DD (except in the Tower results), it is not certain that these tasks can successfully discriminate between subjects. Therefore, a ROC curve analysis and a binary logistic regression analysis were also performed to determine which EF independently contributed to distinguishing between children with DD and TDC. As shown in Table 3, only the Trail-B test showed moderate accuracy (ROC curve analysis), with an AUC of .730 (i.e., a randomly selected child with DD will take more time to complete the Trail-B than a randomly selected child from the TDC group approximately $73 \%$ of the time), while the remaining tasks showed low accuracy.

The goodness-of-fit test of the binary logistic regression analysis yielded a HosmerLemeshow $\chi^{2}(8)=5.495, p=.704$, suggesting that the model fit the data well. A Cox and Snell $R^{2}=.241$ and a Nagelkerke $R^{2}=.322$ were also found. This binary logistic regression model of the four EF tasks correctly classified $71.7 \%$ of the participants according to their DD diagnosis: 69.4\% true-positive (sensitivity), 74\% true-negative (specificity), 26\% falsepositive, and 30.6\% false-negative. As shown in Table 3, only the Trail-B score was a significant predictor, with an odds ratio of $1.015\left(=e^{0.015}\right)$. This result indicates that each onesecond increase of the Trail-B score increased a child's odds of being in the DD group by $1.5 \%$. For example, an increase of 10 seconds on the Trail-B test increases the odds from 1 to $1.161\left(=e^{10 * 0.015}\right)$

(Table 3 about here) 


\section{Discussion}

EF encompasses a set of inter-related processes necessary for goal-directed behavior. These processes develop throughout childhood and adolescence, are largely mediated by the prefrontal and the temporal cortex of the brain, and regulate other cognitive processes. Unsurprisingly, some aspects of EF have been associated with academic achievement (ClairThompson \& Gathercole, 2006; Thorell, Veleiro, Siu, \& Mohammadi, 2012) and reading ability (Foy \& Mann, 2013; Sesma et al., 2009) and may therefore play an important role in DD (Altemeier et al., 2008; Booth, Boyle, \& Kelly, 2010).

The first main objective of the present study was to analyze the performance of Portuguese TDC and children with DD on EF tasks. As expected, based on previous studies from other orthographies, our findings showed the presence of specific EF deficits in children with DD; the results revealed significant differences on PS, shifting, and VF tasks. Larger effect sizes were observed in analyses of the Trail-B, Semantic and Phonemic VF results, suggesting that children with DD may exhibit more deficits on EF tasks that place greater demands on switching abilities and verbal skills. The finding that DD is associated with slower PS and shifting replicates other studies that used the same measures (Narhi et al., 1997; Willcutt et al., 2005) and with those that used different measures (Boets et al., 2010; Shanahan et al., 2006) that incorporated a verbal component of PS (rapid automatized naming) and shifting (rapid alternating stimulus). Non-significant differences were found for all ToL scores, indicating that planning and problem-solving abilities are not compromised in children with DD. This finding is consistent with previous studies examining children with DD (Brosnan et al., 2002; Marzocchi et al., 2008; Reiter et al., 2005) or reading difficulties (Sikora, Haley, Edwards, \& Butler, 2002). This non-significant group difference in planning ability may also be related to the presence of a ceiling effect in two of the three ToL scores 
(Correct Models score and Total Trials score). No interaction of group and gender and/or age was found for any of the EF tasks.

Because the mean WISC-III GAI scores of TDC and DD were significantly different, we additionally examined whether general intellectual ability could explain group differences on EF tasks. The main effect of group remained significant for shifting, VF and marginally significant for PS. The significant main effect on two of the three PS tasks was eliminated after controlling for WISC-III GAI, suggesting that Coding and Trail-A difficulties associated with DD are explained by group differences in general intellectual ability. Whereas some researchers suggest that general intellectual ability should be statistically controlled in cognitive studies of neurodevelopmental disorders, other researchers propose that this approach is misguided and unjustified (for a review, see Dennis et al., 2009; Willcutt et al., 2013).

A more detailed analysis was performed on the results of the two VF tasks. Despite the existence of statistically significant differences between groups (TDC > children with DD) on both the semantic and phonemic VF tasks (as observed in other studies: Landerl et al., 2009; Marzocchi et al., 2008), both groups scored significantly higher on the semantic than the phonemic VF task. This confirms the results of previous studies (Filippetti \& Allegri, 2011; Martins et al., 2007; Reiter et al., 2005), corroborating the consensus that the phonemic VF task is more difficult, possibly because it requires the exploration of more category subsets, relies more on the central executive component of working memory, and it is more dependent on the frontal lobe (Birn et al., 2010). As suggested by Troyer (2000) and Hurks et al. (2004; 2006), the pattern of word production over time is relevant to understanding the specific cognitive mechanisms that underlie poor performance on VF tasks. Our results revealed that there is a significant decrease in the number of words produced among both groups (children with DD and TDC) and on both tasks (semantic and phonemic) as a function of time (over 
four time intervals), which is congruent with the model of lexical organization proposed by Crowe (1998). This model states that in the first period, a ready pool of frequently used words is available and is automatically active for production (automatic processing), but as time passes, the pool becomes exhausted and the search for new words becomes both more effortful and less productive (controlled processing). Notably, significant group differences were only observed in the first two time intervals (TDC > children with DD), suggesting that poor performance on VF tasks among children with DD was particularly related to deficits in automatic processing. Recently, Takács et al. (2014) also found that TDC and children with ADHD generated the largest number of correct responses during the first two time intervals and that significant group differences were only observed in the first quarter. Similarly, Hurks et al. (2004) also observed that children with ADHD generated fewer words (phonemic VF) in the first 15 seconds than did healthy controls and children with other psychopathologies. The authors suggested that children with ADHD may have a developmental delay in automatic processing of abstract verbal information.

Because the presence of a significant difference alone does not indicate that a test can discriminate among subjects with sufficient accuracy for clinical use, the second main objective of the study was to analyze the accuracy with which the EF measures under study discriminate between children with DD and TDC. The results of the ROC curve analysis yielded low diagnostic accuracy for all the tests except Trail-B. The binary logistic regression model, however, yielded an accuracy rate of $71.7 \%$ in classifying children into their correct group (Trail-B was the only significant predictor). No previous studies appear to have analyzed the utility of the different EF processes in diagnosing DD. Although the results highlighted the presence of specific EF deficits in children with DD, they should not be interpreted as indicative of the presence or absence of this learning disorder. As Willcutt et al. (2008, p. 202) stated "EF weakness are neither necessary or sufficient to cause any of the 
disorders (...), and are instead one important component of the complex neuropsychology of childhood disorders". Indeed, the information obtained from EF measures should only be a component of the neuropsychological evaluation and decision-making process and need to be viewed in the context of a more comprehensive assessment that includes other measures, such as phonological awareness, rapid naming, working memory, reading, and spelling measures.

Notwithstanding the uniqueness of the present study, it had several limitations that should be addressed in future studies. First, some of the EFs were assessed only by one task. Clearly the inclusion of more tasks per component would have increased the construct validity and interpretability of the results. Second, the inclusion of other EF tasks (e.g., inhibition, updating, working memory) would also contribute to a better understanding of executive functioning deficits in children with DD. Third, the performance of children with DD on EF tasks was only compared to a TDC group (chronological-age-matched controls) and did not include other clinical samples or a reading-level-matched control group. The literature has clearly demonstrated that children with ADHD also exhibit deficits in a wide range of EF measures (Frazier, Demaree, \& Youngstrom, 2004; Fuggetta, 2006), and that DD and ADHD co-occur more frequently than would be expected by chance ( $15 \%$ to $40 \%$ of individuals with DD meet criteria for ADHD) (Willcutt \& Pennington, 2000). Furthermore, recent studies proposed a multiple cognitive deficit model of neurodevelopmental disorders and found that DD and ADHD shared neurocognitive deficits (McGrath et al., 2011; Willcutt et al., 2005). Thus, future studies should include ADHD children with and without comorbidity with DD in order to increase the generalizability of the findings.

\section{References}


Alexander, M. P., \& Stuss, D. T. (2000). Disorders of frontal lobe functioning. Seminars in Neurology, 20(4), 427-438. doi: 10.1055/s-2000-13175

Altemeier, L. E., Abbott, R. D., \& Berninger, V. W. (2008). Executive functions for reading and writing in typical literacy development and dyslexia. Journal of Clinical and Experimental Neuropsychology, 30(5), 588-606. doi: 10.1080/13803390701562818

American Psychiatric Association. (2013). Diagnostic and statistical manual of mental disorders ( $5^{\text {th }}$ ed.). Washington, DC: Author.

Anderson, P. (2002). Assessment and development of executive function (EF) during childhood. Child Neuropsychology, 8(2), 71-82. doi: 10.1076/chin.8.2.71.8724

Anderson, V., Anderson, P., Northam, E., Jacobs, R., \& Catroppa, C. (2001). Development of executive functions through late childhood and adolescence in an Australian sample. Developmental Neuropsychology, 20, 385-406. doi: 10.1207/S15326942DN2001_5

Aron, A. R., Robbins, T. W., \& Poldrack, R. A. (2004). Inhibition and the right inferior frontal cortex. Trends in Cognitive Sciences, 8(4), 170-177. doi:

10.1016/j.tics.2004.02.010

Baldo, J. V., Schwartz, S., Wilkins, D., \& Dronkers, N. F. (2006). Role of frontal versus temporal cortex in verbal fluency as revealed by voxel-based lesion symptom mapping. Journal of the International Neuropsychological Society, 12(6), 896-900. doi: $10.1017 / \mathrm{S} 1355617706061078$

Baron, I. S. (2004). Neuropsychological evaluation of the child. New York: Oxford University Press.

Bedard, A.-C., Nichols, S., Barbosa, J. A., Schachar, R., Logan, G. D., \& Tannock, R. (2002). The development of selective inhibitory control across the life span. Developmental Neuropsychology, 21(1), 93-111. doi: 10.1207/S15326942DN2101_5 
Bental, B., \& Tirosh, E. (2007). The relationship between attention, executive functions and reading domain abilities in attention deficit hyperactivity disorder and reading disorder: A comparative study. Journal of Child Psychology and Psychiatry, 48(5), 455-463. doi: 10.1111/j.1469-7610.2006.01710.x

Best, J. R., \& Miller, P. H. (2010). A developmental perspective on executive function. Child Development, 81(6), 1641-1660. doi: 10.1111/j.1467-8624.2010.01499.x

Birn, R. M., Kenworthy, L., Case, L., Caravella, R., Jones, T. B., Bandettini, P. A., \& Martin, A. (2010). Neural systems supporting lexical search guided by letter and semantic category cues: A self-paced overt response fMRI study of verbal fluency. NeuroImage, 49(1), 1099-1107. doi: 10.1016/j.neuroimage.2009.07.036

Blakemore, S.-J., \& Choudhury, S. (2006). Development of the adolescent brain: Implications for executive function and social cognition. Journal of Child Psychology and Psychiatry, 47(3-4), 296-312. doi: 10.1111/j.1469-7610.2006.01611.x

Bloom, J. S., Garcia-Barrera, M. A., Miller, C. J., Miller, S. R., \& Hynd, G. W. (2013). Planum temporale morphology in children with developmental dyslexia. Neuropsychologia, 51(9), 1684-1692. doi: 10.1016/j.neuropsychologia.2013.05.012

Boets, B., de Smedt, B., Cleuren, L., Vandewalle, E., Wouters, J., \& Ghesquière, P. (2010). Towards a further characterization of phonological and literacy problems in Dutchspeaking children with dyslexia. British Journal of Developmental Psychology, 28(1), 5-31. doi: 10.1348/026151010x485223

Boets, B., Op de Beeck, H. P., Vandermosten, M., Scott, S. K., Gillebert, C. R., Mantini, D., . . Ghesquière, P. (2013). Intact but less accessible phonetic representations in adults with dyslexia. Science, 342(6163), 1251-1254. doi: 10.1126/science.1244333

Booth, J. N., Boyle, J. M. E., \& Kelly, S. W. (2010). Do tasks make a difference? Accounting for heterogeneity of performance of children with reading difficulties on tasks of 
executive function: Findings from a meta-analysis. British Journal of Developmental Psychology, 28(1), 133-176. doi: 10.1348/026151009x485432

Borella, E., \& de Ribaupierre, A. (2014). The role of working memory, inhibition, and processing speed in text comprehension in children. Learning and Individual Differences. doi: 10.1016/j.lindif.2014.05.001

Brosnan, M., Demetre, J., Hamill, S., Robson, K., Shepherd, H., \& Cody, G. (2002). Executive functioning in adults and children with developmental dyslexia. Neuropsychologia, 40(12), 2144-2155. doi: 10.1016/S0028-3932(02)00046-5

Carvalho, A., \& Pereira, M. (2009). O Rei - Um teste para avaliação da fluência e precisão da leitura no $1^{\circ}$ e $2^{\circ}$ ciclos do Ensino Básico [The King - Assessment test of the reading fluency and precision in the first and second cycles of elementary school]. Psychologica, 51, 283-305.

Catts, H. W., Gillispie, M., Leonard, L. B., Kail, R. V., \& Miller, C. A. (2002). The role of speed of processing, rapid naming, and phonological awareness in reading achievement. Journal of Learning Disabilities, 35(6), 510-525. doi: $10.1177 / 00222194020350060301$

Chan, R. C. K., Shum, D., Toulopoulou, T., \& Chen, E. Y. H. (2008). Assessment of executive functions: Review of instruments and identification of critical issues. Archives of Clinical Neuropsychology, 23(2), 201-216. doi: 10.1016/j.acn.2007.08.010

Clair-Thompson, H. L., \& Gathercole, S. E. (2006). Executive functions and achievements in school: Shifting, updating, inhibition, and working memory. The Quarterly Journal of Experimental Psychology, 59(4), 745-759. doi: 10.1080/17470210500162854

Cohen, M. J., Morgan, A. M., Vaughn, M., Riccio, C. A., \& Hall, J. (1999). Verbal fluency in children: Developmental issues and differential validity in distinguishing children with 
Attention-Deficit Hyperactivity Disorder and two subtypes of Dyslexia. Archives of Clinical Neuropsychology, 14(5), 433-443. doi: 10.1016/s0887-6177(98)00038-9

Collette, F., Hogge, M., Salmon, E., \& Van der Linden, M. (2006). Exploration of the neural substrates of executive functioning by functional neuroimaging. Neuroscience, 139(1), 209-221. doi: 10.1016/j.neuroscience.2005.05.035

Condor, A., Anderson, V., \& Saling, M. (1995). Do reading disabled children have planning problems? Developmental Neuropsychology, 11(4), 485-502. doi: $10.1080 / 87565649509540633$

Crone, E. A., Wendelken, C., Donohue, S. E., \& Bunge, S. A. (2006). Neural evidence for dissociable components of task-switching. Cerebral Cortex, 16(4), 475-486. doi: 10.1093/cercor/bhi127

Crowe, S. F. (1998). Decrease in performance on the verbal fluency test as a function of time: Evaluation in a young healthy sample. Journal of Clinical and Experimental Neuropsychology, 20(3), 391-401. doi: 10.1076/jcen.20.3.391.810

Davidson, M. C., Amso, D., Anderson, L. C., \& Diamond, A. (2006). Development of cognitive control and executive functions from 4 to 13 years: Evidence from manipulations of memory, inhibition, and task switching. Neuropsychologia, 44(11), 2037-2078. doi: 10.1016/j.neuropsychologia.2006.02.006

De Bellis, M. D., Keshavan, M. S., Beers, S. R., Hall, J., Frustaci, K., Masalehdan, A., .. . Boring, A. M. (2001). Sex differences in brain maturation during childhood and adolescence. Cerebral Cortex, 11(6), 552-557. doi: 10.1093/cercor/11.6.552

Demakis, G. J. (2004). Frontal lobe damage and tests of executive processing: A metaanalysis of the Category Test, Stroop Test, and Trail-Making Test. Journal of Clinical and Experimental Neuropsychology, 26(3), 441-450. doi:

$10.1080 / 13803390490510149$ 
Dennis, M., Francis, D. J., Cirino, P. T., Schachar, R., Barnes, M. A., \& Fletcher, J. M. (2009). Why IQ is not a covariate in cognitive studies of neurodevelopmental disorders. Journal of the International Neuropsychological Society, 15(03), 331-343. doi: $10.1017 / \mathrm{S} 1355617709090481$

Fawcett, T. (2006). An introduction to ROC analysis. Pattern Recognition Letters, 27(8), 861874. doi: 10.1016/j.patrec.2005.10.010

Filippetti, V. A., \& Allegri, R. F. (2011). Verbal fluency in Spanish-speaking children: Analysis model according to task type, clustering, and switching strategies and performance over time. The Clinical Neuropsychologist, 25(3), 413-436. doi: $10.1080 / 13854046.2011 .559481$

Foy, J. G., \& Mann, V. A. (2013). Executive function and early reading skills. Reading and Writing, 26(3), 453-472. doi: 10.1007/s11145-012-9376-5

Frazier, T. W., Demaree, H. A., \& Youngstrom, E. A. (2004). Meta-analysis of intellectual and neuropsychological test performance in attention-deficit/hyperactivity disorder. Neuropsychology, 18(3), 543-555. doi: 10.1037/0894-4105.18.3.543

Frijters, J. C., Lovett, M. W., Steinbach, K. A., Wolf, M., Sevcik, R. A., \& Morris, R. D. (2011). Neurocognitive predictors of reading outcomes for children with reading disabilities. Journal of Learning Disabilities, 44(2), 150-166. doi: $10.1177 / 0022219410391185$

Fuggetta, G. P. (2006). Impairment of executive functions in boys with attention deficit/hyperactivity disorder. Child Neuropsychology, 12(1), 1-21. doi: $10.1080 / 09297040500203418$

Giedd, J. N., Snell, J. W., Lange, N., Rajapakse, J. C., Casey, B. J., Kozuch, P. L., . . . Rapoport, J. L. (1996). Quantitative magnetic resonance imaging of human brain development: Ages 4-18. Cerebral Cortex, 6(4), 551-559. doi: 10.1093/cercor/6.4.551 
Gooch, D., Snowling, M., \& Hulme, C. (2011). Time perception, phonological skills and executive function in children with dyslexia and/or ADHD symptoms. Journal of Child Psychology and Psychiatry, 52(2), 195-203. doi: 10.1111/j.14697610.2010.02312.x

Helland, T., \& Asbjørnsen, A. (2000). Executive functions in dyslexia. Child Neuropsychology, 6(1), 37-48. doi: 10.1076/0929-7049(200003)6:1;1-b;ft037

Horowitz-Kraus, T. (2012). Pinpointing the deficit in executive functions in adolescents with dyslexia performing the Wisconsin Card Sorting Test: An ERP study. Journal of Learning Disabilities, doi: 10.1177/0022219412453084. doi:

\section{$10.1177 / 0022219412453084$}

Huizinga, M., Dolan, C. V., \& van der Molen, M. W. (2006). Age-related change in executive function: Developmental trends and a latent variable analysis. Neuropsychologia, 44(11), 2017-2036. doi: 10.1016/j.neuropsychologia.2006.01.010

Hurks, P. P. M. (2012). Does instruction in semantic clustering and switching enhance verbal fluency in children? The Clinical Neuropsychologist, 26(6), 1019-1037. doi: $10.1080 / 13854046.2012 .708361$

Hurks, P. P. M., Hendriksen, J. G. M., Vles, J. S. H., Kalff, A. C., Feron, F. J. M., Kroes, M., . . . Jolles, J. (2004). Verbal fluency over time as a measure of automatic and controlled processing in children with ADHD. Brain and Cognition, 55(3), 535-544. doi: 10.1016/j.bandc.2004.03.003

Hurks, P. P. M., Vles, J. S. H., Hendriksen, J. G. M., Kalff, A. C., Feron, F. J. M., \& Kroes, M. (2006). Semantic category fluency versus initial letter fluency over 60 seconds as a measure of automatic and controlled processing in healthy school-aged children. Journal of Clinical and Experimental Neuropsychology, 28(5), 684-695. doi: $10.1080 / 13803390590954191$ 
Jurado, M. B., \& Rosselli, M. (2007). The elusive nature of executive functions: A review of our current understanding. Neuropsychology Review, 17(3), 213-233. doi: $10.1007 / \mathrm{s} 11065-007-9040-\mathrm{Z}$

Kaufman, A. S., \& Lichtenberger, E. O. (2000). Essentials of WISC-III and WPPSI-R assessment. New York: John Wiley \& Sons, Inc.

Landerl, K., Fussenegger, B., Moll, K., \& Willburger, E. (2009). Dyslexia and dyscalculia: Two learning disorders with different cognitive profiles. Journal of Experimental Child Psychology, 103(3), 309-324. doi: 10.1016/j.jecp.2009.03.006

Landerl, K., Ramus, F., Moll, K., Lyytinen, H., Leppänen, P. H. T., Lohvansuu, K., . . . Schulte-Körne, G. (2013). Predictors of developmental dyslexia in European orthographies with varying complexity. Journal of Child Psychology and Psychiatry, 54(6), 686-694. doi: 10.1111/jcpp.12029

Lehto, J. E., Juujärvi, P., Kooistra, L., \& Pulkkinen, L. (2003). Dimensions of executive functioning: Evidence from children. British Journal of Developmental Psychology, 21(1), 59-80. doi: 10.1348/026151003321164627

Lezak, M. D., Howieson, D. B., \& Loring, D. W. (2004). Neuropsychological assessment. New York: Oxford University Press.

Lyon, G. R., Shaywitz, S., \& Shaywitz, B. (2003). Defining dyslexia, comorbidity, teachers' knowledge of language and reading. Annals of Dyslexia, 53(1), 1-14. doi: $10.1007 / \mathrm{s} 11881-003-0001-9$

Martins, I. P., Maruta, C., Freitas, V., \& Mares, I. (2013). Executive performance in older Portuguese adults with low education. The Clinical Neuropsychologist, 27(3), 410425. doi: $10.1080 / 13854046.2012 .748094$ 
Martins, I. P., Vieira, R., Loureiro, C., \& Santos, M. E. (2007). Speech rate and fluency in children and adolescents. Child Neuropsychology, 13(4), 319-332. doi: $10.1080 / 09297040600837370$

Marzocchi, G. M., Oosterlaan, J., Zuddas, A., Cavolina, P., Geurts, H., Redigolo, D., .. . Sergeant, J. A. (2008). Contrasting deficits on executive functions between ADHD and reading disabled children. Journal of Child Psychology and Psychiatry, 49(5), 543-552. doi: 10.1111/j.1469-7610.2007.01859.x

McGrath, L. M., Pennington, B. F., Shanahan, M. A., Santerre-Lemmon, L. E., Barnard, H. D., Willcutt, E. G., ... Olson, R. K. (2011). A multiple deficit model of reading disability and attention-deficit/hyperactivity disorder: Searching for shared cognitive deficits. Journal of Child Psychology and Psychiatry, 52(5), 547-557. doi: $10.1111 / \mathrm{j} .1469-7610.2010 .02346 . x$

McGrew, K. S. (2009). CHC theory and the human cognitive abilities project: Standing on the shoulders of the giants of psychometric intelligence research. Intelligence, 37(1), 1-10. doi: $10.1016 /$ j.intell.2008.08.004

Menghini, D., Finzi, A., Benassi, M., Bolzani, R., Facoetti, A., Giovagnoli, S., . . Vicari, S. (2010). Different underlying neurocognitive deficits in developmental dyslexia: A comparative study. Neuropsychologia, 48(4), 863-872. doi:

10.1016/j.neuropsychologia.2009.11.003

Miyake, A., Friedman, N. P., Emerson, M. J., Witzki, A. H., Howerter, A., \& Wager, T. D. (2000). The unity and diversity of executive functions and their contributions to complex "frontal lobe" tasks: A latent variable analysis. Cognitive Psychology, 41(1), 49-100. doi: 10.1006/cogp.1999.0734

Moura, O., Simões, M. R., \& Pereira, M. (2013). Fluência verbal semântica e fonémica em crianças: Funções cognitivas e análise temporal [Semantic and phonemic verbal 
fluency in children: Cognitive functions and temporal analysis]. Avaliação Psicológica, 12(2), 167-177.

Moura, O., Simões, M. R., \& Pereira, M. (2014a). WISC-III cognitive profiles in children with developmental dyslexia: Specific cognitive disability and diagnostic utility. Dyslexia, 20(1), 19-37. doi: 10.1002/dys.1468

Moura, O., Simões, M. R., \& Pereira, M. (2014b). Working memory in Portuguese children with developmental dyslexia. Applied Neuropsychology: Child. doi: $10.1080 / 21622965.2014 .885389$

Narayanan, N. S., Prabhakaran, V., Bunge, S. A., Christoff, K., Fine, E. M., \& Gabrieli, J. D. (2005). The role of the prefrontal cortex in the maintenance of verbal working memory: An event-related FMRI analysis. Neuropsychology, 19(2), 223-232. doi: $10.1037 / 0894-4105.19 .2 .223$

Narhi, V., Rasanen, P., Metsapelto, R.-L., \& Ahonen, T. (1997). Trail Making Test in assessing children with reading disabilities: A test of executive functions or content information. Perceptual and Motor Skills, 84(3c), 1355-1362. doi: 10.2466/pms.1997.84.3c. 1355

Peng, P., Sha, T., \& Li, B. (2013). The deficit profile of working memory, inhibition, and updating in Chinese children with reading difficulties. Learning and Individual Differences, doi: 10.1016/j.lindif.2013.1001.1012. doi: 10.1016/j.lindif.2013.01.012

Pennington, B. F. (2006). From single to multiple deficit models of developmental disorders. Cognition, 101(2), 385-413. doi: 10.1016/j.cognition.2006.04.008

Prifitera, A., Weiss, L. G., \& Saklofske, D. H. (1998). The WISC-III in context. In A. Prifitera \& D. H. Saklofske (Eds.), WISC-III clinical use and interpretation: Scientistpractitioner perspectives (pp. 1-38). New York: Academic Press. 
Ramus, F., Marshall, C. R., Rosen, S., \& van der Lely, H. K. J. (2013). Phonological deficits in specific language impairment and developmental dyslexia: Towards a multidimensional model. Brain, 136(2), 630-645. doi: 10.1093/brain/aws356

Reiter, A., Tucha, O., \& Lange, K. W. (2005). Executive functions in children with dyslexia. Dyslexia, 11(2), 116-131. doi: 10.1002/dys.289

Riva, D., Nichelli, F., \& Devoti, M. (2000). Developmental aspects of verbal fluency and confrontation naming in children. Brain and Language, 71(2), 267-284. doi: 10.1006/brln.1999.2166

Rosselli, M., Ardila, A., Bateman, J. R., \& Guzman, M. (2001). Neuropsychological test scores, academic performance, and developmental disorders in Spanish-speaking children. Developmental Neuropsychology, 20(1), 355-373. doi: $10.1207 / \mathrm{s} 15326942 \mathrm{dn} 2001 \_3$

Saklofske, D. H., Prifitera, A., Weiss, L. G., Rolfhus, E., \& Zhu, J. (2005). Clinical interpretation of the WISC-IV FSIQ and GAI. In A. Prifitera, D. H. Saklofske \& L. G. Weiss (Eds.), WISC-IV clinical use and interpretation: Scientist-practitioner perspectives (pp. 33-65). New York: Elsevier Academic Press.

Sala, S. D., Gray, C., Spinnler, H., \& Trivelli, C. (1998). Frontal lobe functioning in man: The riddle revisited. Archives of Clinical Neuropsychology, 13(8), 663-682. doi: 10.1093/arclin/13.8.663

Sesma, H. W., Mahone, E. M., Levine, T., Eason, S. H., \& Cutting, L. E. (2009). The contribution of executive skills to reading comprehension. Child Neuropsychology, 15(3), 232-246. doi: 10.1080/09297040802220029

Shanahan, M. A., Pennington, B. F., Yerys, B. E., Scott, A., Boada, R., Willcutt, E. G., . . . DeFries, J. C. (2006). Processing speed deficits in attention deficit/hyperactivity 
disorder and reading disability. Journal of Abnormal Child Psychology, 34(5), 584601. doi: 10.1007/s10802-006-9037-8

Sikora, D. M., Haley, P., Edwards, J., \& Butler, R. W. (2002). Tower of London test performance in children with poor arithmetic skills. Developmental Neuropsychology, 21(3), 243-254. doi: 10.1207/s15326942dn2103_2

Simões, M. R., Albuquerque, C. P., Pinho, M. S., Pereira, M., Seabra-Santos, M. J., Alberto, I., . . . Lopes, A. F. (in press). Bateria de Avaliação Neuropsicológica de Coimbra (BANC) [Coimbra Neuropsychological Assessment Battery]. Lisboa: Cegoc.

Stuss, D. T., \& Alexander, M. P. (2000). Executive functions and the frontal lobes: A conceptual view. Psychological Research, 63(3-4), 289-298. doi: $10.1007 / \mathrm{s} 004269900007$

Swanson, H. L. (2011). Dynamic testing, working memory, and reading comprehension growth in children with reading disabilities. Journal of Learning Disabilities, 44(4), 358-371. doi: 10.1177/0022219411407866

Swets, J. A. (1988). Measuring the accuracy of diagnostic systems. Science, 240(4857), 12851293. doi: $10.1126 /$ science. 3287615

Takács, Á., Kóbor, A., Tárnok, Z., \& Csépe, V. (2014). Verbal fluency in children with ADHD: Strategy using and temporal properties. Child Neuropsychology, 20(4), 415429. doi: $10.1080 / 09297049.2013 .799645$

Tamnes, C. K., Østby, Y., Walhovd, K. B., Westlye, L. T., Due-Tønnessen, P., \& Fjell, A. M. (2010). Neuroanatomical correlates of executive functions in children and adolescents: A magnetic resonance imaging (MRI) study of cortical thickness. Neuropsychologia, 48(9), 2496-2508. doi: 10.1016/j.neuropsychologia.2010.04.024

Thomson, M. (2003). Monitoring dyslexics' intelligence and attainments: A follow-up study. Dyslexia, 9(1), 3-17. doi: 10.1002/dys.232 
Thorell, L. B., Veleiro, A., Siu, A. F. Y., \& Mohammadi, H. (2012). Examining the relation between ratings of executive functioning and academic achievement: Findings from a cross-cultural study. Child Neuropsychology, doi:

10.1080/09297049.09292012.09727792. doi: 10.1080/09297049.2012.727792

Troyer, A. K. (2000). Normative data for clustering and switching on verbal fluency task. Journal of Clinical and Experimental Neuropsychology, 22(3), 370-378. doi: 10.1076/1380-3395(200006)22:3;1-V;FT370

Troyer, A. K., Moskovitch, M., \& Winocur, G. (1997). Clustering and switching as two components of verbal fluency: Evidence from younger and older health adults. Neuropsychology, 11(1), 138-146. doi: 10.1037/0894-4105.11.1.138

Unsworth, N., Spillers, G. J., \& Brewer, G. A. (2010). Variation in verbal fluency: A latent variable analysis of clustering, switching, and overall performance. The Quarterly Journal of Experimental Psychology, 64(3), 447-466. doi:

$10.1080 / 17470218.2010 .505292$

van den Wildenberg, W. P. M., \& van der Molen, M. W. (2004). Developmental trends in simple and selective inhibition of compatible and incompatible responses. Journal of Experimental Child Psychology, 87(3), 201-220. doi: 10.1016/j.jecp.2003.11.003

van der Sluis, S., de Jong, P. F., \& van der Leij, A. (2004). Inhibition and shifting in children with learning deficits in arithmetic and reading. Journal of Experimental Child Psychology, 87(3), 239-266. doi: 10.1016/j.jecp.2003.12.002

van der Sluis, S., de Jong, P. F., \& van der Leij, A. (2007). Executive functioning in children, and its relations with reasoning, reading, and arithmetic. Intelligence, 35(5), 427-449. doi: 10.1016/j.intell.2006.09.001 
Varvara, P., Varuzza, C., Sorrentino, A. C. P., Vicari, S., \& Menghini, D. (2014). Executive functions in developmental dyslexia. Frontiers in Human Neuroscience, 8. doi: 10.3389/fnhum.2014.00120

Wager, T., \& Smith, E. (2003). Neuroimaging studies of working memory. Cognitive, Affective, \& Behavioral Neuroscience, 3(4), 255-274. doi: 10.3758/CABN.3.4.255

Wasserman, T., \& Wasserman, L. D. (2013). Toward an integrated model of executive functioning in children. Applied Neuropsychology: Child, 2(2), 88-96. doi: $10.1080 / 21622965.2013 .748394$

Wechsler, D. (2003). Wechsler Intelligence Scale for Children (WISC-III) - Portuguese Version (M. R. Simões, A. M. Rocha, and C. Ferreira). Lisbon: Cegoc.

Welsh, M. C., Pennington, B. F., \& Groisser, D. B. (1991). A normative-developmental study of executive function: A window on prefrontal function in children. Developmental Neuropsychology, 7(2), 131-149. doi: 10.1080/87565649109540483

Willcutt, E. G., \& Pennington, B. F. (2000). Comorbidity of reading disability and attentiondeficit/hyperactivity disorder: Differences by gender and subtype. Journal of Learning Disabilities, 33(2), 179-191. doi: 10.1177/002221940003300206

Willcutt, E. G., Pennington, B. F., Olson, R. K., Chhabildas, N., \& Hulslander, J. (2005). Neuropsychological analyses of comorbidity between reading disability and attention deficit hyperactivity disorder: In search of the common deficit. Developmental Neuropsychology, 27(1), 35-78. doi: 10.1207/s15326942dn2701_3

Willcutt, E. G., Petrill, S. A., Wu, S., Boada, R., DeFries, J. C., Olson, R. K., \& Pennington, B. F. (2013). Comorbidity between reading disability and math disability: Concurrent psychopathology, functional impairment, and neuropsychological functioning. Journal of Learning Disabilities, 46(6), 500-516. doi: 10.1177/0022219413477476 
Willcutt, E. G., Sonuga-Barke, E., Nigg, J., \& Sergeant, J. (2008). Recent developments in neuropsychological models of childhood psychiatric disorders. Advances in Biological Psychiatry, 24, 195-226. doi: 10.1159/000118526

Yeniad, N., Malda, M., Mesman, J., van Ijzendoorn, M. H., \& Pieper, S. (2013). Shifting ability predicts math and reading performance in children: A meta-analytical study. Learning and Individual Differences, 23(1), 1-9. doi: 10.1016/j.lindif.2012.10.004 
Table 1. Means and Standard Deviations of Executive Functions for Typically Developing Children and Children with Developmental Dyslexia

\begin{tabular}{|c|c|c|c|c|c|c|c|c|c|c|c|c|c|c|c|c|}
\hline & \multicolumn{8}{|c|}{ Typically Developing Children } & \multicolumn{8}{|c|}{ Children with Developmental Dyslexia } \\
\hline & \multirow{2}{*}{ Total } & \multicolumn{2}{|c|}{ Gender } & \multicolumn{5}{|c|}{ Age } & \multirow{2}{*}{ Total } & \multicolumn{2}{|c|}{ Gender } & \multicolumn{5}{|c|}{ Age } \\
\hline & & Male & Female & 8 & 9 & 10 & 11 & 12 & & Male & Female & 8 & 9 & 10 & 11 & 12 \\
\hline \multicolumn{17}{|l|}{ Processing Speed } \\
\hline Coding $^{\mathrm{ss}}$ & $\begin{array}{l}11.12 \\
(2.70)\end{array}$ & $\begin{array}{l}10.91 \\
(2.64)\end{array}$ & $\begin{array}{l}11.50 \\
(2.85)\end{array}$ & $\begin{array}{l}12.57 \\
(1.61)\end{array}$ & $\begin{array}{l}10.74 \\
(2.42)\end{array}$ & $\begin{array}{l}12.13 \\
(3.04)\end{array}$ & $\begin{array}{l}11.00 \\
(3.11)\end{array}$ & $\begin{array}{c}9.88 \\
(3.09)\end{array}$ & $\begin{array}{c}9.61 \\
(2.45)\end{array}$ & $\begin{array}{c}9.33 \\
(2.57)\end{array}$ & $\begin{array}{l}10.38 \\
(1.98)\end{array}$ & $\begin{array}{c}9.63 \\
(3.24)\end{array}$ & $\begin{array}{l}10.12 \\
(2.64)\end{array}$ & $\begin{array}{c}8.88 \\
(1.45)\end{array}$ & $\begin{array}{l}10.29 \\
(1.97)\end{array}$ & $\begin{array}{c}8.78 \\
(2.43)\end{array}$ \\
\hline Symbol Search ${ }^{\text {ss }}$ & $\begin{array}{l}10.96 \\
(3.12)\end{array}$ & $\begin{array}{l}10.94 \\
(3.41)\end{array}$ & $\begin{array}{l}11.00 \\
(2.61)\end{array}$ & $\begin{array}{l}12.71 \\
(3.63)\end{array}$ & $\begin{array}{l}10.95 \\
(2.36)\end{array}$ & $\begin{array}{l}12.00 \\
(3.46)\end{array}$ & $\begin{array}{c}9.50 \\
(3.50)\end{array}$ & $\begin{array}{c}9.88 \\
(3.18)\end{array}$ & $\begin{array}{c}9.31 \\
(2.64)\end{array}$ & $\begin{array}{c}9.42 \\
(2.41)\end{array}$ & $\begin{array}{c}9.00 \\
(3.29)\end{array}$ & $\begin{array}{l}10.50 \\
(2.97)\end{array}$ & $\begin{array}{l}10.06 \\
(2.30)\end{array}$ & $\begin{array}{c}8.13 \\
(2.35)\end{array}$ & $\begin{array}{c}7.57 \\
(3.59)\end{array}$ & $\begin{array}{c}9.22 \\
(1.56)\end{array}$ \\
\hline Trail-A & $\begin{array}{c}37.14 \\
(16.00)\end{array}$ & $\begin{array}{c}38.06 \\
(17.49)\end{array}$ & $\begin{array}{c}35.50 \\
(13.26)\end{array}$ & $\begin{array}{c}47.29 \\
(11.77)\end{array}$ & $\begin{array}{c}44.26 \\
(19.64)\end{array}$ & $\begin{array}{l}30.12 \\
(3.39)\end{array}$ & $\begin{array}{l}26.75 \\
(5.44)\end{array}$ & $\begin{array}{r}28.75 \\
(11.84)\end{array}$ & $\begin{array}{c}43.28 \\
(14.39)\end{array}$ & $\begin{array}{c}44.59 \\
(14.73)\end{array}$ & $\begin{array}{c}39.54 \\
(13.17)\end{array}$ & $\begin{array}{c}53.89 \\
(12.98)\end{array}$ & $\begin{array}{c}43.71 \\
(15.43)\end{array}$ & $\begin{array}{c}47.50 \\
(14.56)\end{array}$ & $\begin{array}{l}38.43 \\
(9.48)\end{array}$ & $\begin{array}{l}31.89 \\
(7.70)\end{array}$ \\
\hline Shifting & & & & & & & & & & & & & & & & \\
\hline Trail-B & $\begin{array}{l}91.12 \\
(31.53)\end{array}$ & $\begin{array}{c}94.78 \\
(33.14)\end{array}$ & $\begin{array}{c}84.61 \\
(28.16)\end{array}$ & $\begin{array}{r}97.86 \\
(11.48)\end{array}$ & $\begin{array}{l}100.00 \\
(33.59)\end{array}$ & $\begin{array}{c}84.75 \\
(36.27)\end{array}$ & $\begin{array}{c}84.13 \\
(29.50)\end{array}$ & $\begin{array}{r}77.50 \\
(34.46)\end{array}$ & $\begin{array}{l}120.12 \\
(40.28)\end{array}$ & $\begin{array}{l}124.32 \\
(42.40)\end{array}$ & $\begin{array}{l}108.15 \\
(31.95)\end{array}$ & $\begin{array}{l}149.78 \\
(35.22)\end{array}$ & $\begin{array}{l}123.24 \\
(44.35)\end{array}$ & $\begin{array}{l}123.75 \\
(17.10)\end{array}$ & $\begin{array}{l}124.86 \\
(39.39)\end{array}$ & $\begin{array}{c}77.67 \\
(16.57)\end{array}$ \\
\hline Planning (Tower) & & & & & & & & & & & & & & & & \\
\hline Correct $1^{\text {st }}$ Trials & $\begin{array}{c}9.76 \\
(1.72)\end{array}$ & $\begin{array}{c}9.91 \\
(1.87)\end{array}$ & $\begin{array}{c}9.50 \\
(1.42)\end{array}$ & $\begin{array}{c}9.71 \\
(1.38)\end{array}$ & $\begin{array}{r}9.42 \\
(1.50)\end{array}$ & $\begin{array}{c}8.50 \\
(1.85)\end{array}$ & $\begin{array}{l}10.88 \\
(1.88)\end{array}$ & $\begin{array}{l}10.75 \\
(1.28)\end{array}$ & $\begin{array}{c}9.22 \\
(1.63)\end{array}$ & $\begin{array}{c}9.24 \\
(1.63)\end{array}$ & $\begin{array}{c}9.15 \\
(1.72)\end{array}$ & $\begin{array}{c}9.00 \\
(1.80)\end{array}$ & $\begin{array}{c}8.76 \\
(1.34)\end{array}$ & $\begin{array}{c}9.50 \\
(1.85)\end{array}$ & $\begin{array}{c}9.14 \\
(1.34)\end{array}$ & $\begin{array}{l}10.11 \\
(1.90)\end{array}$ \\
\hline Correct Models & $\begin{array}{l}13.64 \\
(0.56)\end{array}$ & $\begin{array}{l}13.63 \\
(0.55)\end{array}$ & $\begin{array}{l}13.67 \\
(0.59)\end{array}$ & $\begin{array}{l}13.57 \\
(0.78)\end{array}$ & $\begin{array}{l}13.63 \\
(0.49)\end{array}$ & $\begin{array}{l}13.50 \\
(0.75)\end{array}$ & $\begin{array}{l}13.88 \\
(0.35)\end{array}$ & $\begin{array}{l}13.63 \\
(0.51)\end{array}$ & $\begin{array}{l}13.54 \\
(0.64)\end{array}$ & $\begin{array}{l}13.59 \\
(0.55)\end{array}$ & $\begin{array}{l}13.38 \\
(0.87)\end{array}$ & $\begin{array}{l}12.89 \\
(0.92)\end{array}$ & $\begin{array}{l}13.53 \\
(0.51)\end{array}$ & $\begin{array}{l}14.00 \\
(0.01)\end{array}$ & $\begin{array}{l}13.57 \\
(0.53)\end{array}$ & $\begin{array}{l}13.78 \\
(0.44)\end{array}$ \\
\hline Total Trials & $\begin{array}{l}20.60 \\
(3.25)\end{array}$ & $\begin{array}{l}20.31 \\
(3.15)\end{array}$ & $\begin{array}{l}21.11 \\
(3.44)\end{array}$ & $\begin{array}{l}20.71 \\
(2.92)\end{array}$ & $\begin{array}{l}21.42 \\
(2.91)\end{array}$ & $\begin{array}{l}22.38 \\
(3.88)\end{array}$ & $\begin{array}{l}18.50 \\
(2.87)\end{array}$ & $\begin{array}{l}18.88 \\
(2.74)\end{array}$ & $\begin{array}{l}21.54 \\
(3.07)\end{array}$ & $\begin{array}{l}21.62 \\
(3.22)\end{array}$ & $\begin{array}{l}21.31 \\
(2.72)\end{array}$ & $\begin{array}{l}23.22 \\
(3.52)\end{array}$ & $\begin{array}{l}21.94 \\
(2.27)\end{array}$ & $\begin{array}{l}20.63 \\
(3.54)\end{array}$ & $\begin{array}{l}21.57 \\
(2.87)\end{array}$ & $\begin{array}{l}19.89 \\
(3.25)\end{array}$ \\
\hline
\end{tabular}


Verbal Fluency

\begin{tabular}{|c|c|c|c|c|c|c|c|c|c|c|c|c|c|c|c|c|}
\hline \multirow[t]{2}{*}{ Semantic } & 50.72 & 50.06 & 51.89 & 52.00 & 43.84 & 57.13 & 52.75 & 57.50 & 44.70 & 43.86 & 47.08 & 38.33 & 42.82 & 42.25 & 51.71 & 51.33 \\
\hline & (10.33) & $(8.87)$ & (12.73) & (7.14) & $(7.84)$ & (7.16) & (11.52) & (11.30) & $(9.87)$ & (10.30) & $(8.46)$ & $(9.56)$ & $(8.00)$ & (11.42) & $(7.54)$ & (8.32) \\
\hline \multirow[t]{2}{*}{ Phonemic } & 22.22 & 22.59 & 21.56 & 18.86 & 18.11 & 24.25 & 29.88 & 25.25 & 18.12 & 18.30 & 17.62 & 13.67 & 16.53 & 18.13 & 21.86 & 22.67 \\
\hline & $(8.39)$ & (7.48) & (10.01) & (7.92) & $(5.92)$ & (8.12) & $(7.75)$ & $(9.16)$ & (6.19) & $(6.00)$ & (6.92) & $(4.00)$ & $(5.49)$ & $(5.71)$ & $(5.92)$ & (6.34) \\
\hline
\end{tabular}

Note. $\mathrm{ss}=$ age-scaled score $(M=10, S D=3)$. All other scores are raw scores. Standard deviations in parentheses. 
Table 2. Repeated Measures ANOVA of Verbal Fluency Over Four Time Intervals

\begin{tabular}{|c|c|c|c|c|c|c|}
\hline & (1) $0-15 \mathrm{~s}$ & (2) $16-30 \mathrm{~s}$ & (3) $31-45 \mathrm{~s}$ & (4) $46-60 \mathrm{~s}$ & Repeated Measures & Pairwise \\
\hline & $M(S D)$ & $M(S D)$ & $M(S D)$ & $M(S D)$ & ANOVA & comparisons $^{*}$ \\
\hline \multicolumn{7}{|c|}{ Semantic VF } \\
\hline \multirow[t]{2}{*}{$\mathrm{TDC}$} & 24.38 & 12.36 & 8.30 & 5.66 & $F(3,147)=535.845$ & $1>2>3>4$ \\
\hline & $(4.44)$ & $(3.00)$ & $(2.60)$ & $(3.15)$ & $p<.001, \eta^{2}=.916$ & \\
\hline \multirow[t]{2}{*}{$\mathrm{DD}$} & 20.96 & 10.74 & 7.84 & 5.24 & $F(3,147)=379.214$ & $1>2>3>4$ \\
\hline & $(4.12)$ & $(3.27)$ & $(3.08)$ & $(2.42)$ & $p<.001, \eta_{\mathrm{p}}^{2}=.886$ & \\
\hline \multicolumn{7}{|c|}{ Phonemic VF } \\
\hline \multirow[t]{2}{*}{$\mathrm{TDC}$} & 10.96 & 4.80 & 3.44 & 3.02 & $F(3,147)=211.141$ & $1>2>3,4$ \\
\hline & $(3.30)$ & $(2.42)$ & $(2.20)$ & $(2.36)$ & $p<.001, \eta_{\mathrm{p}}^{2}=.812$ & \\
\hline \multirow[t]{2}{*}{$\mathrm{DD}$} & 9.30 & 3.56 & 2.86 & 2.34 & $F(3,147)=160.869$ & $1>2,3,4 ; 2>4$ \\
\hline & $(3.11)$ & $(1.93)$ & $(1.78)$ & $(1.61)$ & $p<.001, \eta_{\mathrm{p}}^{2}=.767$ & \\
\hline
\end{tabular}

Note. ${ }^{*}$ Bonferroni adjustment for multiple comparisons $(p<.05) ;$ TDC $=$ typically developing children; DD $=$ children with developmental dyslexia; VF = verbal fluency. 
Table 3. Receiver Operating Characteristics Curve Analysis and Binary Logistic Regression

\begin{tabular}{|c|c|c|c|c|c|}
\hline & \multicolumn{2}{|c|}{ ROC Curve Analysis } & \multicolumn{3}{|c|}{ Binary Logistic Regression Analysis } \\
\hline & $\operatorname{AUC}(95 \% \mathrm{CI})$ & $S E$ & $\beta$ & Wald's $\chi^{2}$ & Odds Ratio \\
\hline \multicolumn{6}{|l|}{ Processing Speed } \\
\hline Coding & $.670(.563-.777)^{* *}$ & .055 & -.110 & 0.931 & 0.896 \\
\hline Symbol Search & $.663(.556-.770)^{* *}$ & .055 & -.148 & 1.989 & 0.863 \\
\hline Trail-A & $.651(.542-.759)^{* *}$ & .055 & .002 & 0.017 & 1.002 \\
\hline \multicolumn{6}{|l|}{ Shifting } \\
\hline Trail-B & $.730(.631-.829)^{* * *}$ & .051 & .015 & $3.940^{*}$ & 1.015 \\
\hline \multicolumn{6}{|l|}{ Planning (Tower) } \\
\hline Correct $1^{\text {st }}$ Trials & $.592(.480-.704)$ & .057 & -.380 & 1.583 & 0.684 \\
\hline Correct Models & $.539(.425-.652)$ & .058 & -.061 & 0.014 & 0.940 \\
\hline Total Trials & $.594(.482-.706)$ & .057 & -.089 & 0.240 & 0.915 \\
\hline \multicolumn{6}{|l|}{ Verbal Fluency } \\
\hline Semantic & $.660(.554-.766)^{* *}$ & .054 & -.013 & 0.192 & 0.987 \\
\hline Phonemic & $.644(.536-.753)^{*}$ & .055 & -.047 & 1.377 & 0.954 \\
\hline
\end{tabular}

Note: ${ }^{*} p<.05, * * p<.01,{ }^{* * *} p<.001 ; \mathrm{ROC}=$ receiver operating characteristics; AUC $=$ area under the curve; $\mathrm{CI}=$ confidence interval; $S E=$ standard error. 